\title{
Periarticular local anaesthetic in knee arthroplasty: A systematic review and meta-analysis of randomised trials
}

\author{
Dr ML Gibbins MBChB, DTMH
}

Anaesthetics and Intensive Care Medicine Specialist Trainee,

Severn Deanery School of Intensive Care Medicine and Anaesthesia, Bristol, United Kingdom

Dr C Kane BA(Hons), MBChB, DA

Core Anaesthetics Trainee, South West Peninsula School of Post Graduate Medical Education, Torquay, United Kingdom Dr RW Smit MBChB, FCOrtho, CIME

Honorary Clinical Associate, Department of Orthopaedics, Grey's Hospital, Pietermaritzburg,

University of KwaZulu-Natal, Durban, South Africa

Dr RN Rodseth MBChB, FCA, MMed, MSc, PhD

Honorary Clinical Associate, Perioperative Research Group, Department of Anaesthetics, Grey's Hospital, Pietermaritzburg, University of KwaZulu-Natal, Durban, South Africa; Department of Outcomes Research, Cleveland Clinic, Cleveland, Ohio, USA

\author{
Corresponding author: \\ Dr Matthew L. Gibbins \\ 78 Pembroke Road, Bristol \\ BS8 3EG, England, United Kingdom \\ Email: gibbins.matt@gmail.com
}

\begin{abstract}
Background: This systematic review and meta-analysis aimed to quantify the effect of adding peri-articular local anaesthetic infiltration or infusion to an analgesic strategy in patients undergoing knee arthroplasty.

Methods: A literature search of six data bases was performed. Randomised controlled trials comparing periarticular local anaesthetic infiltration/infusion against other analgesic strategies in adult patients undergoing knee arthroplasty were included. The primary outcome was resting Visual Analogue Scores 24 hours after surgery.

Results: In the review, 396 potential studies were identified, of which 35 full text articles were assessed for eligibility. A total of 770 patients from 12 trials were included in the final meta-analysis. Local anaesthetic addition significantly improved pain control (mean difference -0.95 [ $95 \% \mathrm{CI}-1.68$ to -0.21$]$ ); however, there was significant heterogeneity (I²: 88\%).

Conclusion: Our analysis suggests that peri-articular local anaesthetic infiltration/infusion improves resting pain scores 24 hours after knee arthroplasty. However, the heterogeneity of these findings urges caution in their interpretation.
\end{abstract}

Key words: local anaesthetic, arthroplasty, knee arthroplasty, knee replacement, intra-articular injections

http:/ / dx.doi.org/10.17159/2309-8309/2016/v15n3a7

\section{Introduction}

The provision of adequate post-operative analgesia in patients undergoing knee arthroplasty presents a significant challenge. A multimodal approach to pain control in these patients has been commonly adopted with regimens including opioids, nonsteroidal anti-inflammatory drugs, adjuncts such as gabapentin or pregabalin, and the use of neuraxial and peripheral nerve blockade. Peri-articular injections and infusion of local anaesthetic holds great attraction as it provides localised analgesia without the side effects often seen with neuraxial or peripheral nerve blockade. This systematic review and meta-analysis aimed to determine whether, in adults undergoing knee arthroplasty, adding peri-articular local anaesthetic to a post-operative pain regimen improved post-operative pain scores. 


\section{Methods}

The PRISMA guidelines were followed in conducting and reporting this review. ${ }^{1}$ The protocol for this review was not registered.

\section{Trial eligibility and identification}

Only randomised controlled trials (RCTs) in adult patients undergoing knee arthroplasty, in which a peri-operative pain regimen including peri-articular local anaesthetic administration which was evaluated using a visual analogue score (VAS), was compared to a regimen without peri-articular local anaesthetic, were considered eligible. Trials were included regardless of language, sample size, publication status, or date of publication. On 19 November 2013, six databases were searched (Embase, Ovid Health Star, Ovid Medline ${ }^{\circledast}$ In-Process \& Other Non-Indexed Citations and Avid Medline ${ }^{\bowtie}$, The Cochrane Library, ProQuest Dissertations and Theses A\&I, and Web of Knowledge). The search terms with key words used were as follows: local anaesthetic; infiltration or infusion or injection; arthroplasty or replacement; knee or knees. Appendix 1 provides an example of the search strategy used. The search was updated on 12 December 2014.

\section{Appendix 1}

\section{Search strategy and databases}

The search terms, including validated prognostic search terms and databases used are listed as follows: Database searches were conducted on 19 November 2013 using the OvidSP search engine (Ovid Technologies, Inc., New York, NY 2009) for the following databases:

1. Embase 1974 to 2013 November 18

2. Ovid Health Star (1966 to October 2013)

3. Ovid Medline ${ }^{\circledast}$ In-Process \& Other Non-Indexed Citations and Avid Medline ${ }^{\circledR} 1946$ to 19 November 2013

4. The Cochrane Library (19 November 2013)

5. ProQuest Dissertations and Theses A\&I (19 November 2013)

6. Web of Knowledge (1976 to November 2013)

\section{Example of search conducted on Medline}

\begin{tabular}{llr}
\hline & Search terms & Number \\
\hline 1 & local anesthetic.mp. & 45648 \\
\hline 2 & (infiltration or infusion or injection).mp. & 1738689 \\
\hline 3 & 1 and 2 & 13643 \\
\hline 4 & (arthroplasty or replacement).mp. & 695783 \\
\hline 5 & (knee or knees).mp. & 328093 \\
\hline 6 & 4 and 5 & 73994 \\
\hline 7 & 3 and 6 & 245 \\
\hline 8 & remove duplicates from 7 & 162 \\
\hline
\end{tabular}

\section{Eligibility assessment}

Working in pairs we independently screened the title and abstract of each citation to identify potentially eligible trials. If either reviewer felt the citation contained a relevant trial, the article was retrieved to undergo full text evaluation. Full texts of all citations identified as being potentially relevant were then independently evaluated to determine eligibility. Disagreements were solved by consensus. Chance corrected inter-observer agreement for trial eligibility was tested using kappa statistics. Only RCTs conducted in adult patients ( $>17$ years of age) undergoing knee arthroplasty where peri-articular local anaesthetic was added to a peri-operative analgesic regimen were considered eligible. The trial outcome had to report visual analogue scores (VAS) at rest at 24 hours after surgery to be included in the final meta-analysis. Where not reported in the text these values, together with their standard deviations, were read from study tables and graphs. Where this data was not available attempts were made to contact trial authors. Abstracts, including meeting abstracts, were not planned for inclusion.

\section{Data collection, assessment of trial quality, bias and outcomes}

For each eligible trial we attempted to extract the outcome of VAS at rest - 24 hours after surgery together with its standard deviation. Where studies included more than two groups we selected data from the control arm not making use of any local anaesthetic and data from the arm with the maximal peri-articular local anaesthetic protocol (i.e. continuous infusion of local anaesthetic was used in preference over a single shot local anaesthetic injection arm). Where trials reported the inter-quartile range and not the standard deviation the standard deviation was estimated to be 0.75 of the width of the interquartile range. ${ }^{2}$ Where bilateral replacements were done pain scores for each knee were evaluated individually.

Trial quality and bias was evaluated using the following criteria: randomisation methodology, completeness of patient follow-up, method of patient follow-up, blinded outcome assessment, consistent endpoint assessment, and the use of intention to treat analysis.

Meta-analysis of the mean difference between pain protocols including peri-articular local anaesthesia and protocols without peri-articular local anaesthesia was conducted using a random effects model in Review Manager Version 5.1. (Copenhagen: The Nordic Cochrane Centre, The Cochrane Collaboration, 2011). Heterogeneity was assessed using I2 and chi-squared analysis. The pooled outcome was reported as a mean difference and $95 \%$ confidence intervals (CI). We constructed a funnel plot to assess for the possibility of publication bias. 


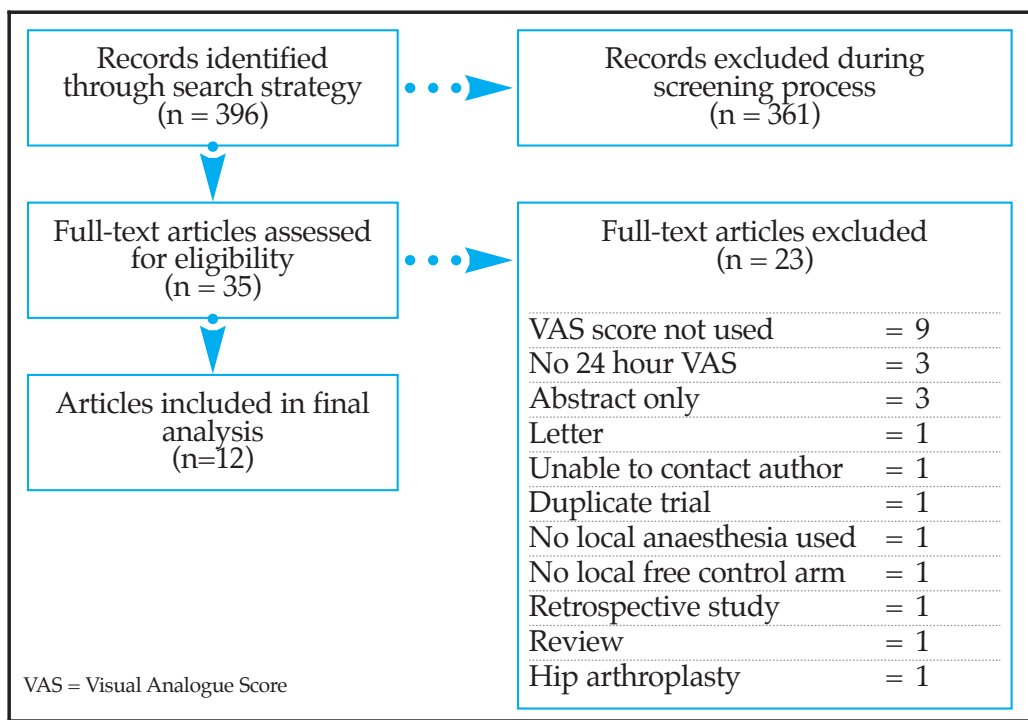

Figure 1. Trial selection process

\section{Results}

\section{Trial identification and selection}

The trial selection process is shown in Figure 1. We identified 396 citations, from which 35 were selected for full-text evaluation. From these we identified 12 eligible RCTs. ${ }^{3-14}$ Inter-observer agreement for trial eligibility was good (kappa $=0.75$; SE 0.053).

Table I reports the characteristics of the included trials and the local anaesthetic protocols used in the trials. Table II reports the details of the comparator analgesic protocols used as well as the background analgesic protocols used for all enrolled patients, and Table III provides the quality characteristics for all included trials.

Table I: Characteristics of local anaesthetic injection and infusion protocols

\begin{tabular}{|c|c|c|c|c|c|}
\hline \multirow{2}{*}{ Author (year) } & \multirow{2}{*}{$\begin{array}{c}\text { Patient } \\
\text { numbers }\end{array}$} & \multicolumn{3}{|c|}{ Periarticular local anaesthetic characteristics } & \multirow{2}{*}{ Notes } \\
\hline & & Infiltration & Adjuncts & Infusion & \\
\hline Andersen $(2010)^{3}$ & 40 & $\begin{array}{c}\text { Ropivacaine } 0.2 \% \\
150 \mathrm{ml}[300 \mathrm{mg}]\end{array}$ & $\begin{array}{l}\text { Adrenaline } 0.5 \mathrm{mg} \\
\text { Ketorolac } 30 \mathrm{mg}\end{array}$ & $\begin{array}{c}\text { Ropivacaine } 0.2 \% \text { at } \\
4 \mathrm{ml} / \mathrm{hr} \text { for } 48 \mathrm{hrs} \\
{[380 \mathrm{mg}]}\end{array}$ & $\begin{array}{l}\text { Injection to deep and superficial tissues } \\
\text { Intra-articular catheter for infusion }\end{array}$ \\
\hline Essving $(2010)^{4}$ & 48 & $\begin{array}{l}\text { Ropivacaine } 0.5 \% \\
80 \mathrm{ml} \text { [400 mg] }\end{array}$ & $\begin{array}{l}\text { Adrenaline } 0.5 \mathrm{mg} \\
\text { Ketorolac } 30 \mathrm{mg}\end{array}$ & $\begin{array}{l}\text { Repeat bolus at } 21 \text { hours } \\
\text { Ropivacaine } 0.5 \% \\
\text { [200 mg] }\end{array}$ & $\begin{array}{l}\text { Initial injection performed before prosthesis } \\
\text { implanted and during closure. Repeat injection at } \\
21 \mathrm{hrs} \text { via drain }\end{array}$ \\
\hline Goyal $(2013)^{5}$ & 150 & - & - & $\begin{array}{l}\text { Bupivacaine } 0.5 \% \text { at } \\
5 \mathrm{ml} / \mathrm{hr}[1500 \mathrm{mg}]\end{array}$ & $\begin{array}{l}\text { Intra-articular catheter. Infusion pump activated } \\
\text { immediately post op }\end{array}$ \\
\hline Han $(2007)^{6}$ & 60 & $\begin{array}{l}\text { Ropivacaine } 0.75 \% \\
\quad 40 \mathrm{ml}[300 \mathrm{mg}]\end{array}$ & $\begin{array}{l}\text { Morphine } 5 \mathrm{mg} \\
\text { Adrenaline } 0.25 \mathrm{ml} \\
\quad \text { 1:200 } 000\end{array}$ & - & $\begin{array}{l}\text { Solution injected into ten different sites around the } \\
\text { synovium before wound closure }\end{array}$ \\
\hline Mauerhan $(1997)^{7}$ & 51 & $\begin{array}{l}\text { Ropivacaine } 50 \mathrm{mg} \\
\text { [concentration/ } \\
\text { volume not specified] }\end{array}$ & - & - & $\begin{array}{l}\text { Solution injected via intra-articular drain after } \\
\text { procedure }\end{array}$ \\
\hline Mullaji $(2010)^{8}$ & 40 & $\begin{array}{l}\text { Bupivacaine } 2 \mathrm{mg} / \mathrm{kg} \\
\text { [concentration/ } \\
\text { volume not specified] }\end{array}$ & $\begin{array}{l}\text { Fentanyl } 100 \mathrm{mcg} \\
\text { Methylprednisolone } 40 \mathrm{mg} \\
\text { Cefuroxime } 750 \mathrm{mg}\end{array}$ & - & Injection performed during cementing \\
\hline Ong $(2010)^{9}$ & 38 & $\begin{array}{l}\text { Bupivacaine } 100 \mathrm{mg} \\
\text { [concentration/ } \\
\text { volume not specified] }\end{array}$ & $\begin{array}{l}\text { Ketorolac } 1 \mathrm{ml} \\
\text { [dose not specified] } \\
\text { Morphine } 10 \mathrm{mg}\end{array}$ & $\begin{array}{l}\text { Bupivacaine } 0.25 \% \text { at } \\
4 \mathrm{ml} / \mathrm{hr} \text { for } 48 \text { hours } \\
\text { [ } 480 \mathrm{mg}]\end{array}$ & $\begin{array}{l}\text { Infusion delivered through two catheters - one } \\
\text { intra-articular, one subcutaneous }\end{array}$ \\
\hline Reinhardt $(2013)^{10}$ & 94 & - & - & $\begin{array}{l}\text { Bupivacaine } 0.2 \% \text { at } \\
7 \mathrm{ml} / \mathrm{hr} \text { for } 48 \text { hours }\end{array}$ & Intra-operative intra-articular insertion \\
\hline Spreng $(2010)^{11}$ & 68 & $\begin{array}{l}\text { Ropivacaine } 0.1 \% \\
150 \mathrm{ml}[150 \mathrm{mg}]\end{array}$ & $\begin{array}{l}0.5 \mathrm{mg} \text { adrenaline, } 30 \mathrm{mg} \\
\text { ketorolac, } 5 \mathrm{mg} \text { morphine } \\
\text { with initial injection }\end{array}$ & $\begin{array}{c}\text { Repeat bolus at } 22-24 \text { hours } \\
\text { Ropivacaine } 0.75 \%-19 \mathrm{ml} \\
{[142.5 \mathrm{mg}]}\end{array}$ & $\begin{array}{l}\text { Injection performed pre-incision, intra-operatively } \\
\text { and } 10 \mathrm{ml} \text { infiltrated into the joint via a catheter } \\
\text { following closure. Further injection after } 22-24 \text { hrs } \\
\text { before removing catheter }\end{array}$ \\
\hline Vendittoli (2006) $)^{12}$ & 42 & $\begin{array}{l}\text { Ropivacaine } 400 \mathrm{mg} \text { [used } \\
\text { in various } \\
\text { concentrations] }\end{array}$ & $\begin{array}{l}\text { Adrenaline } 0.5 \mathrm{mg} \\
\text { Ketorolac } 30 \mathrm{mg}\end{array}$ & $\begin{array}{l}\text { Repeat bolus on day one } \\
\text { Ropivacaine } 150 \mathrm{mg}\end{array}$ & $\begin{array}{l}\text { Deep and subcutaneous tissues injected intra- } \\
\text { operatively. Further injection performed via catheter } \\
\text { into intra-articular space }\end{array}$ \\
\hline Williams $(2013)^{13}$ & 67 & $\begin{array}{l}\text { Bupivacaine } \\
025 \%-20 \mathrm{ml}[50 \mathrm{mg}]\end{array}$ & $\begin{array}{l}\text { Adrenaline } \\
\text { [dose not specified] }\end{array}$ & $\begin{array}{c}\text { Bupivacaine } 0.5 \% \text { at } \\
2 \mathrm{ml} / \mathrm{hr} \text { for } 48 \mathrm{hrs}[480 \mathrm{mg}]\end{array}$ & $\begin{array}{l}\text { Initial injection divided between intra-articular and } \\
\text { subcutaneous tissue during closure. Infusion via } \\
\text { intra-articular catheter }\end{array}$ \\
\hline Zhang $(2011)^{14}$ & 64 & $\begin{array}{c}\text { Ropivacaine } \\
0.2 \%-150 \mathrm{ml}[300 \mathrm{mg}]\end{array}$ & $\begin{array}{l}\text { Adrenaline } 0.5 \mathrm{mg} \\
\text { Ketorolac } 30 \mathrm{mg}\end{array}$ & $\begin{array}{l}\text { Ropivacaine } 0.2 \% \text { [380 mg] } \\
\text { Ketorolac } 60 \mathrm{mg} \text { at } \\
4 \mathrm{~ms} / \mathrm{hr} \text { for } 48 \mathrm{hrs}\end{array}$ & $\begin{array}{l}\text { Injection divided between deep and superficial } \\
\text { tissues. Infusion via intra-articular catheter }\end{array}$ \\
\hline
\end{tabular}




\section{Table II: Characteristics of comparator and background analgesic protocols}

\begin{tabular}{|c|c|c|}
\hline Author (year) & Comparator analgesic protocol & Background analgesic protocol for all patients \\
\hline Andersen $(2010)^{3}$ & $\begin{array}{l}\text { Combined spinal epidural }-7 \mathrm{ml} \text { bolus of } 0.2 \% \text { ropivacaine followed by } \\
\text { infusion at } 4 \mathrm{ml} / \mathrm{hr} \text { for } 48 \mathrm{hr} \text {, with } 5 \text { doses IV ketorolac [total } 90 \mathrm{mg} \text { ] }\end{array}$ & Paracetamol and morphine PCA as breakthrough analgesia \\
\hline Essving $(2010)^{4}$ & Intra-articular saline injection at $21 \mathrm{hr}$ only & Morphine PCA, paracetamol and tramadol for breakthrough analgesia \\
\hline Goyal $(2013)^{5}$ & Saline infusion & $\begin{array}{l}\text { Paracetamol, pregabalin and celecoxib } 2 \mathrm{hr} \text { post op, with regular paracetamol, } \\
\text { ketorolac and pregabalin. Breakthrough analgesia provided by any of: } \\
\text { tramadol, codeine, fentanyl PCA, oxycodone, hydromorphine (IV/PO) }\end{array}$ \\
\hline Han $(2007)^{6}$ & Saline infusion & $\begin{array}{l}\text { Epidural infusion/PCEA of } 0.225 \% \text { ropivacaine, } 1 \mathrm{mcg} / \mathrm{ml} \text { sufentanil and } \\
5 \mathrm{mcg} / \mathrm{kg} \text { of naloxone [in } 100 \mathrm{ml}] \text { at } 2 \mathrm{ml} / \mathrm{hr} \text { with } 0.5 \mathrm{ml} \text { bolus available at } \\
15 \mathrm{minute} \text { intervals. IV tramadol was available as rescue analgesia }\end{array}$ \\
\hline Mauerhan $(1997)^{7}$ & Saline infusion & All patients had access to morphine [or meperidine if nauseous] PCA post-op \\
\hline Mullaji (2010) & [no specific comparator protocol] & $\begin{array}{l}\text { Etoricoxib pre-op, epidural infusion of } 3.6 \mathrm{mg} \text { bupivacaine and } 4 \mathrm{mcg} \text { fentanyl } \\
\text { per } \mathrm{ml} \text { at } 2 \mathrm{ml} / \mathrm{hr} \text { and regular tramadol/paracetamol/diclofenac }\end{array}$ \\
\hline Ong $(2010)^{9}$ & [no specific comparator protocol] & Etirocoxib, paracetamol and morphine PCA \\
\hline Reinhardt $(2013)^{10}$ & $\begin{array}{l}\text { Intra-operatively - combined spinal epidural (hydromorphone and } \\
\text { bupivacaine) and femoral nerve block ( } 30 \mathrm{ml} 0.25 \% \text { bupivacaine) } \\
\text { Post-operatively continuous epidural at } 4 \mathrm{ml} / \mathrm{hr} \text { with a } 4 \mathrm{mg} \text { demand dose }\end{array}$ & $\begin{array}{l}\text { Pre-operative meloxicam and dexamethasone. Post-operatively - meloxicam } \\
15 \mathrm{mg} \text {, ketorolac, acetaminophen and oxycodone, and hydromorphone for } \\
\text { breakthrough pain }\end{array}$ \\
\hline Spreng $(2010)^{11}$ & $\begin{array}{l}\text { Epidural infusion [rate based on height] containing } 2 \mathrm{mcg} / \mathrm{ml} \text { fentanyl, } \\
1 \mathrm{mcg} / \mathrm{ml} \text { epinephrine and } 1 \mathrm{mg} / \mathrm{ml} \text { bupivacaine for } 48 \mathrm{hr}\end{array}$ & Paracetamol 6 hourly and morphine PCA for breakthrough analgesia \\
\hline Vendittoli $(2006)^{12}$ & [no specific comparator protocol] & $\begin{array}{l}\text { Regular celecoxib and paracetamol, and morphine PCA for breakthrough } \\
\text { analgesia }\end{array}$ \\
\hline Williams $(2013)^{13}$ & Saline infusion & $\begin{array}{l}\text { Regular ketorolac, gabapentin, paracetamol and oxycodone, and morphine } \\
\text { PCA for breakthrough analgesia }\end{array}$ \\
\hline Zhang $(2011)^{14}$ & Saline infusion & $\begin{array}{l}\text { All patients received celecoxib and morphine PCA, with IM morphine as } \\
\text { rescue analgesia }\end{array}$ \\
\hline
\end{tabular}

$\mathrm{PCA}=$ patient controlled analgesia, $\mathrm{IM}=$ intra-muscular, $\mathrm{IV}=$ intravenous; $\mathrm{PO}=$ per os

\section{Table III: Study quality characteristics}

\begin{tabular}{|c|c|c|c|c|c|c|}
\hline Author (year) & Randomisation & $\begin{array}{l}\text { Patients with } \\
\text { complete } \\
\text { follow-up (\%) }\end{array}$ & Method of patient follow-up & $\begin{array}{l}\text { Blinded } \\
\text { outcome } \\
\text { assessment }\end{array}$ & $\begin{array}{l}\text { Consistent } \\
\text { end-point } \\
\text { assessment }\end{array}$ & $\begin{array}{l}\text { Intention to } \\
\text { treat analysis }\end{array}$ \\
\hline Andersen $(2010)^{3}$ & $\begin{array}{l}\text { Randomised, double-blind, } \\
\text { placebo-controlled }\end{array}$ & $100 \%$ & Direct patient contact & Yes & Yes & Yes \\
\hline Essving $(2010)^{4}$ & $\begin{array}{l}\text { Randomised, double-blind } \\
\text { (computer-generated } \\
\text { randomised numbers) }\end{array}$ & $98 \%(n=47)$ & $\begin{array}{l}\text { Direct patient contact, Oxford knee score } \\
\text { questionnaire \& EuroCol questionnaire }\end{array}$ & Yes & Yes & No \\
\hline Goyal $(2013)^{5}$ & $\begin{array}{l}\text { Randomised, double-blind, } \\
\text { placebo-controlled }\end{array}$ & $100 \%$ & $\begin{array}{l}\text { Direct patient contact \& pain management } \\
\text { questionnaire inc. VAS scales \& reporting of } \\
\text { opioid-related symptoms, narcotic consumption } \\
\text { from medical records \& follow-up questionnaire at } \\
4 \text { weeks post-operatively }\end{array}$ & Yes & Yes & No \\
\hline $\operatorname{Han}(2007)^{6}$ & Randomised, double-blind & $100 \%$ & Direct patient contact & Yes & Yes & Yes \\
\hline Mauerhan $(1997)^{7}$ & Randomised, double-blind & $100 \%$ & Direct patient contact & Yes & Yes & No \\
\hline Mullaji $(2010)^{8}$ & Randomised, double-blind & $100 \%$ & Direct patient contact & Yes & Yes & Yes \\
\hline Ong $(2010)^{9}$ & Randomised, double-blind & $100 \%$ & Direct patient contact & Yes & Yes & Yes \\
\hline Reinhardt $(2013)^{10}$ & Randomised, double-blind & $100 \%$ & Direct patient contact & Yes & Yes & No \\
\hline Spreng $(2010)^{11}$ & Randomised, double-blind & $97 \%(\mathrm{n}=66)$ & $\begin{array}{l}\text { Direct patient contact \& interview } \\
\text { prior to discharge }\end{array}$ & Yes & Yes & No \\
\hline Vendittoli $(2006)^{12}$ & Randomised, double-blind & $100 \%$ & Direct patient contact & Yes & Yes & No \\
\hline Williams $(2013)^{13}$ & Randomised, double-blind & $73 \%(n=49)$ & $\begin{array}{l}\text { Direct patient contact, morphine consumption, } \\
\text { length of hospital stay. Also range of motion, Knee } \\
\text { Society and Oxford Knee Scores recorded up to one } \\
\text { year post-operatively }\end{array}$ & Yes & Yes & No \\
\hline Zhang $(2011)^{14}$ & Randomised, double-blind & $83 \%(\mathrm{n}=53)$ & Direct patient contact & Yes & Yes & No \\
\hline
\end{tabular}




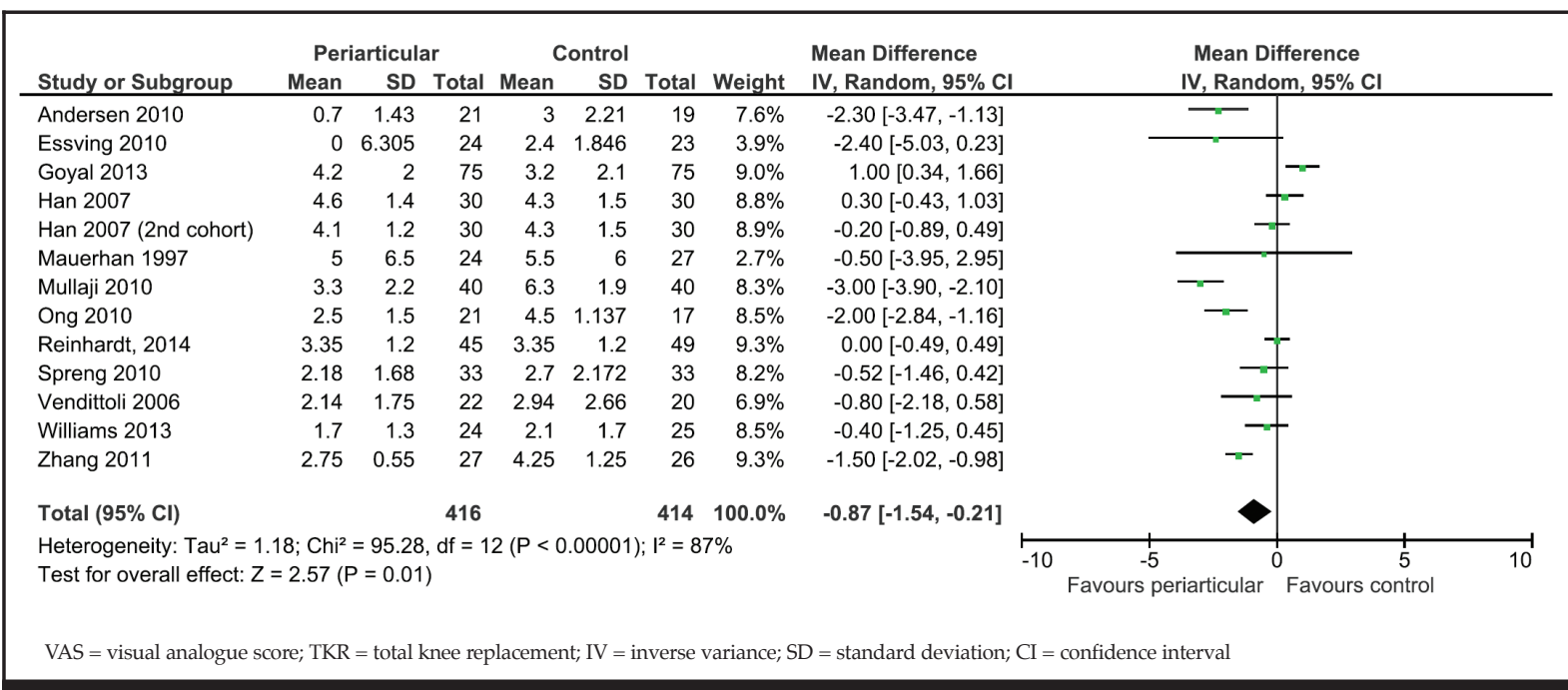

Figure 2. Forest plot of the mean VAS score difference in TKR patients receiving peri-articular local anaesthetic injection or infusion as compared to regimens without peri-articular local anaesthetic

\section{Study outcomes}

The VAS score at 24 hours was reported in all included trials and provided a total of 386 patients receiving periarticular local anaesthetic and 384 patients receiving other peri-operative analgesia. Patients who received peri-articular local anaesthetic showed a statistically significant reduction in their pain score at 24 hours after surgery (mean difference $-0.95 ; 95 \%$ CI -1.68 to $-0.21 ; \mathrm{I}^{2}=88 \%$ ) (Figure 2). The funnel plot for the analysis is shown in Figure 3 and shows a lack of reporting bias among the selected trials.

\section{Discussion}

\section{Statement of principle findings}

Our meta-analysis of 12 RCTs, which included a total of 770 patients, found that the addition of peri-articular local anaesthetic infiltration or infusion (LAi) to a postoperative analgesic regimen resulted in a statistically significant reduction in VAS pain scores at 24 hours after total knee arthroplasty (mean difference -0.95 ; 95\% CI -1.68 to $-0.21 ; \mathrm{I}^{2}=88 \%$ ).

\section{Strengths}

We performed a rigorous search of the databases to ensure all published and non-published studies were identified. Only RCTs reporting objective measures of pain were included and inter-observer agreement for inclusion of trials was good. Where trials were thought to be eligible, but did not include the relevant outcome measures or we were unable to locate the full text article, every effort was made to contact the authors to obtain the required information.

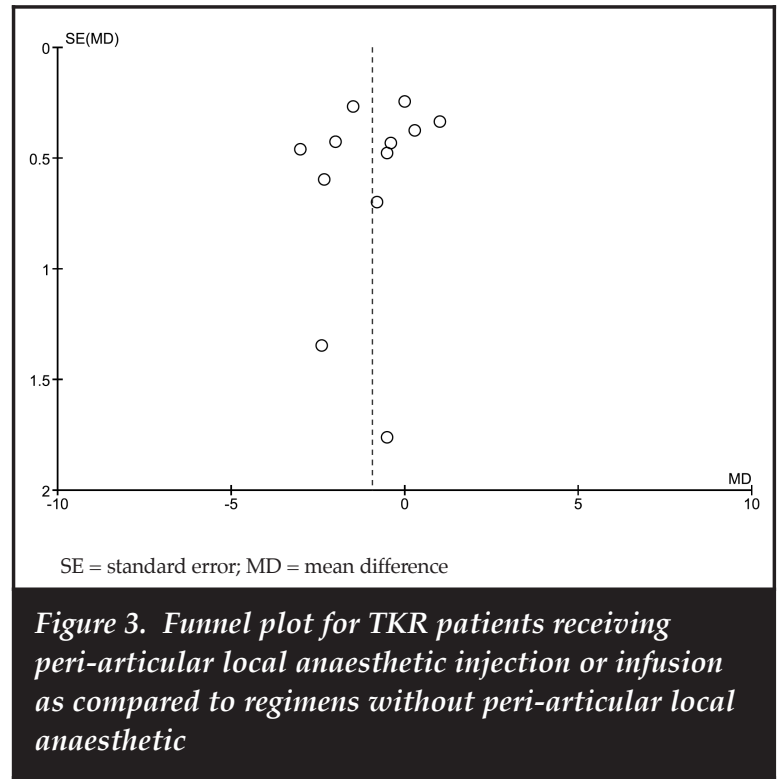

\section{Weaknesses}

Despite a rigorous search of six databases, the possibility that relevant RCTs may have been missed cannot be excluded.

Pain is a subjective entity and as result difficult to quantify and measure. VAS is a validated method of measuring pain, and as a result we only included studies using this method. This led to the exclusion of 12 studies (nine as VAS was not used and three as no VAS score was reported at 24 hours), thus potentially significant data was excluded. We felt this unavoidable as to perform a meta-analysis an objective outcome common to all studies is required. Several studies used Numeric Rating Scales (NRS) to assess pain. As there is likely correlation between the two methods, we considered converting NRS into VAS equivalents. However, 
VAS uses a continuous scale whereas NRS uses an interval scale and we could find no validated method with which to perform the conversion. Therefore studies using NRS were not included as we felt it may undermine the reliability of our meta-analysis. Despite our best efforts, one trial was excluded as we were unable to locate the full article or contact the author - once again potentially excluding significant data.

Several trials included VAS scores but the data (mean and standard deviation) was not expressed numerically. Efforts were made to contact the authors for the relevant information; however, where the numerical data was unobtainable we calculated it from graphs provided..$^{12}$ These attempts to extract the relevant data introduce a risk of error in measurement. However, we felt the risk of this error was outweighed by the benefit of being able to include the data within the meta-analysis.

$\mathrm{I}^{2}$ and chi-squared analysis revealed significant heterogeneity between the trials included in the meta-analysis. There are several factors that likely contribute to the observed heterogeneity. The outcomes sought in this review more likely follow a skewed, non-normal distribution as confirmed by authors of the three most methodologically rigorous studies. As pooling of data for meta-analysis involves normally distributed data, converting median and interquartile range (IQR) to mean and SD will introduce a degree of uncertainty in the estimate of effect.

The trials included in this analysis have used a wide variety of interventions to provide post-operative analgesia for total knee arthroplasty. However, it is important to note that despite these differences the addition of LAi to any regimen resulted in a reduction in post-operative pain scores. This, together with the unique mechanism by which local anaesthesia provides analgesia, and the lack of reporting bias shown in the funnel plot, suggests that these findings reflect a true additive analgesic effect over and above other analgesic modalities.

\section{This study in relation to other studies and future research}

In 2014, Andersen and Kehlet published a systematic review of the analgesic efficacy of local infiltration analgesia in hip and knee arthroplasty. ${ }^{15}$ Their analysis of the literature comprised individual comparisons of local anaesthetic injection to placebo, peripheral nerve block, epidural and systemic analgesia. They concluded that in total knee arthroplasty, most randomised controlled clinical trials demonstrated improved analgesia in patients receiving LAi, even in combination with multimodal systemic analgesia, particularly within the early post-operative period - thus supporting the findings of our meta-analysis. However, their review highlighted the variability between the studies and some of the methodological pitfalls commonly encountered; many studies were vulnerable to confounding and bias due to incomplete blinding, variations in background analgesia between intervention and control groups and the lack of control for the systemic effects of drugs included within the local anaesthetic injectate - such as NSAIDs. They also stated that 'the lack of a ... meta-analysis of study outcome measures' may be a limitation to their review.

Andersen et al. themselves performed a randomised double-blind placebo controlled trial assessing LAi versus placebo in 12 consecutive patients undergoing bilateral TKR, thus providing the optimum controls and eliminating many of the confounding issues experienced by other trials. ${ }^{16}$ This study was excluded from our final metaanalysis as VAS pain scores were not used. However, despite its small study size, it can be considered one of the more methodologically rigorous trials assessing the benefit of LAi and it found a statistically significant reduction in Numeric Rating Scale (NRS) pain scores in patients receiving LAi up to 25 hours post-operatively at rest and 32 hours post-operatively upon 45 degrees flexion.

Owing to the use of NRS and not VAS to assess pain, only one study in the final meta-analysis included femoral nerve block in the comparator protocol. Of those studies excluded, Affas et al. performed an RCT of 40 patients comparing intra-operative local anaesthetic infiltration to pre- and post-operative femoral nerve block (via a perineural catheter). ${ }^{17}$ They reported a marginal reduction in pain at rest in the group receiving local anaesthetic infiltration (NRS 1.6 vs 2.1), a statistically significant increase in incidence of intense pain in the femoral nerve block group $(1 / 20$ vs $7 / 19$ patients reporting an NRS pain score of $>7, \mathrm{p}=0.04)$ and concluded that although both methods provided good analgesia, local anaesthetic infiltration 'may be considered to be superior to femoral nerve block as it is cheaper and easier'. These findings are supported by Toftdahl et al., who, in their RCT of 80 patients found that those receiving peri-articular infiltration and postoperative infusion of local anaesthetic had lower morphine consumption ( $83 \mathrm{mg}$ vs $100 \mathrm{mg}, \mathrm{p}=0.02$ ) and improved mobility on the first post-operative day ( $29 / 39$ vs $7 / 27$ able to walk $>3 \mathrm{~m}, \mathrm{p}<0.001){ }^{18}$ However, both Affas and Toftdahl's studies may be subject to bias due to a lack of blinding. Carli et al.'s double-blind RCT of 40 patients reported decrease morphine consumption $(14.5 \mathrm{mg}$ vs $26 \mathrm{mg}, \mathrm{p}=0.02$ ) and improved six-week recovery (assessed by several criteria) in those receiving continuous femoral nerve block compared to peri-articular local anaesthetic infiltration. ${ }^{19}$

Of the trials included in our final meta-analysis we consider Andersen ${ }^{3}$ and Williams ${ }^{13}$ to have been the most methodologically robust. Andersen performed an RCT comparing LAi (infiltration and 48-hour infusion) to continuous epidural infusion, controlling for the systemic effects of ketorolac in the local anaesthetic mixture and providing identical background analgesic protocols for both groups. They demonstrated a statistically significant reduction in morphine consumption (median $11 \mathrm{mg}$ vs $33 \mathrm{mg}$ at 48 hours) and VAS pain scores (median $5 \mathrm{~mm}$ vs $33 \mathrm{~mm}$ at $24-48$ hours) in the LAi group. Williams's double-blind RCT compared continuous infusion of local anaesthetic for 48 hours to saline infusion. 
They reported a non-significant reduction in morphine consumption (mean $39 \mathrm{mg}$ vs $53 \mathrm{mg}$ at 48 hours, $\mathrm{p}=0.137$ ) and VAS pain scores (mean 1.7 vs 2.1 at 24 hours $p=0.386$ ) in the intervention group. However, both intervention and control groups received local anaesthetic infiltration intraoperatively.

As well as improved analgesia, one of the perceived benefits of LAi over other techniques is a potentially lower side-effect profile and improved motor function of the operated limb, resulting in earlier and improved rehabilitation. Ilfeld's review of three RCTs in 2010 suggests a causal link between continuous femoral nerve block and patient falls following total knee arthroplasty ${ }^{20}$ and Andersen reported a statistically significant increase in urinary retention and constipation in the epidural group compared to LAi. ${ }^{3}$ Vendittoli in 2006 analysed the plasma concentrations of local anaesthetic following LAi and reported that all plasma concentrations were below the toxic range. ${ }^{12}$ Neither Andersen nor Venditolli reported any complications directly related to LAi, suggesting it is a safe method of providing analgesia.

Andersen and Kehlet's systematic review also reported on length of hospital stay; however, this varied widely and was unrelated to the method of analgesia used. ${ }^{15}$ Moreover, whether the cause of increase in length of stay was related to pain or not was not reported by any of the studies analysed. As far as we are aware there are no large, high quality studies into the cost effectiveness of Lai; however, the simplicity of the procedure and decreased systemic analgesic requirements demonstrated by some studies imply it may be a cost-effective method of providing analgesia. ${ }^{3,12}$

There was significant variation in the technique of performing LAi between the studies included in our metaanalysis, which may have contributed to the heterogeneity. Variations include the precise location of single intraoperative injections, the content of injectate and the use of post-operative infusions and boluses via catheters. Several studies have been performed by Andersen into the optimum technique for LAi, including the location of the injection, the concentration and volume of injectate and the use of bandages to improve spread ${ }^{21-25}$ and Williams et al. demonstrated no significant benefit from a 48-hour infusion of local anaesthetic following intra-operative infiltration. ${ }^{13}$ However, there is still little consensus as to the optimum technique. Standardising the procedure of LAi would assist in performing future research into not only the efficacy of LAi for total knee arthroplasty, but also its safety, and cost effectiveness.

Although a degree of caution should be exercised when interpreting the result of our meta-analysis due to the heterogeneity identified, we believe it strongly supports the inclusion of LAi as part of the analgesic regimen for patients undergoing total knee arthroplasty. Further research should focus on the optimum technique of local anaesthetic infiltration and the benefits of additional postoperative infusion.

\section{Compliance with Ethics Guidelines \\ Competing interests:}

Funding: Dr Rodseth is supported by the National Research Foundation of South Africa and the College of Medicine of South Africa.

Conflicts of interest: None to declare.

Declarations: This work has not been previously submitted or presented in any form.

\section{References}

1. Available from: http:/ / www.prisma-statement.org/index.htm.

2. Higgins JP, Altman DG, Gotzsche PC, Juni P, Moher D, Oxman $\mathrm{AD}$, et al. The Cochrane Collaboration's tool for assessing risk of bias in randomised trials. BMJ (Clinical research ed). 2011;343:d5928.

3. Andersen KV, Bak M, Christensen BV, Harazuk J, Pedersen NA, Soballe K. A randomized, controlled trial comparing local infiltration analgesia with epidural infusion for total knee arthroplasty. Acta Orthopaedica. 2010;81(5):606-10.

4. Essving P, Axelsson K, Kjellberg J, Wallgren O, Gupta A, Lundin A. Reduced morphine consumption and pain intensity with local infiltration analgesia (LIA) following total knee arthroplasty. Acta Orthopaedica. 2010;(3):354-60.

5. Goyal N, McKenzie J, Sharkey PF, Parvizi J, Hozack WJ, Austin MS. The 2012 Chitranjan Ranawat award: intraarticular analgesia after TKA reduces pain: a randomized, double-blinded, placebo-controlled, prospective study. Clinical Orthopaedics and Related Research. 2013;(1):64-75.

6. Han $\mathrm{CD}$, Lee DH, Yang IH. Intra-synovial ropivacaine and morphine for pain relief after total knee arthroplasty: a prospective, randomized, double blind study. Yonsei Medical Journal. 2007;(2):295-300.

7. Mauerhan DR, Campbell M, Miller JS, Mokris JG, Gregory A, Kiebzak GM. Intra-articular morphine and/or bupivacaine in the management of pain after total knee arthroplasty. The Journal of Arthroplasty. 1997;(5):546-52.

8. Mullaji A, Kanna R, Shetty GM, Chavda V, Singh DP. Efficacy of periarticular injection of bupivacaine, fentanyl, and methylprednisolone in total knee arthroplasty. A prospective, randomized trial. Journal of Arthroplasty. 2010;25(6):851-57.

9. Ong JC, Lin CP, Fook-Chong SM, Tang A, Ying YK, Keng TB. Continuous infiltration of local anaesthetic following total knee arthroplasty. Journal of Orthopaedic Surgery (Hong Kong). 2010;18(2):203-207.

10. Reinhardt KR, Duggal S, Umunna BP, Reinhardt GA, Nam $\mathrm{D}$, Alexiades $\mathrm{M}$, et al. Intraarticular analgesia versus epidural plus femoral nerve block after TKA: a randomized, double-blind trial. Clin Orthop Relat Res. 2014;472(5): 1400-408

11. Spreng UJ, Dahl V, Hjall A, Fagerland MW, Raeder J. Highvolume local infiltration analgesia combined with intravenous or local ketorolac plus morphine compared with epidural analgesia after total knee arthroplasty. British Journal of Anaesthesia. 2010;105(5):675-82.

12. Vendittoli PA, Makinen P, Drolet P, Lavigne M, Fallaha M, Guertin MC, et al. A multimodal analgesia protocol for total knee arthroplasty: A randomized, controlled study. Journal of Bone and Joint Surgery - Series A. 2006;88 (2):282-89. 
13. Williams D, Petruccelli D, Paul J, Piccirillo L, Winemaker $\mathrm{M}$, de Beer J. Continuous infusion of bupivacaine following total knee arthroplasty: a randomized control trial pilot study. Journal of Arthroplasty. 2013;28(3):479-84.

14. Zhang S, Wang F, Lu ZD, Li YP, Zhang L, Jin QH. Effect of single-injection versus continuous local infiltration analgesia after total knee arthroplasty: a randomized, double-blind, placebo-controlled study. The Journal of International Medical Research. 2011;(4):1369-80.

15. Andersen LO, Kehlet H. Analgesic efficacy of local infiltration analgesia in hip and knee arthroplasty: a systematic review. Br J Anaesth. 2014;113(3):360-74.

16. Andersen LO, Husted H, Otte KS, Kristensen BB, Kehlet H. High-volume infiltration analgesia in total knee arthroplasty: a randomized, double-blind, placebo-controlled trial. Acta anaesthesiologica Scandinavica. 2008;52(10):1331-35.

17. Affas F, Nygårds EB, Stiller CO, Wretenberg P, Olofsson C. Pain control after total knee arthroplasty: a randomized trial comparing local infiltration anesthesia and continuous femoral block. Acta Orthopaedica. 2011;(4):441-47.

18. Toftdahl K, Nikolajsen L, Haraldsted V, Madsen F, Tonnesen EK, Soballe K. Comparison of peri- and intraarticular analgesia with femoral nerve block after total knee arthroplasty: a randomized clinical trial. Acta Orthop. 2007;78(2):172-79.

19. Carli F, Clemente A, Asenjo JF, Kim DJ, Mistraletti G, Gomarasca M, et al. Analgesia and functional outcome after total knee arthroplasty: periarticular infiltration vs continuous femoral nerve block. $\mathrm{Br} J$ Anaesth. 2010;105(2):185-95.
20. Ilfeld BM, Duke KB, Donohue MC. The association between lower extremity continuous peripheral nerve blocks and patient falls after knee and hip arthroplasty. Anesthesia and analgesia. 2010;111(6):1552-54.

21. Andersen LO, Gaarn-Larsen L, Kristensen BB, Husted H, Otte KS, Kehlet H. Analgesic efficacy of local anaesthetic wound administration in knee arthroplasty: volume vs concentration. Anaesthesia. 2010;65(10):984-90.

22. Andersen LO, Husted H, Kristensen BB, Otte KS, GaarnLarsen L, Kehlet H. Analgesic efficacy of subcutaneous local anaesthetic wound infiltration in bilateral knee arthroplasty: A randomised, placebo-controlled, double-blind trial. Acta anaesthesiologica Scandinavica. 2010;54(5):543-48.

23. Andersen L, Husted H, Otte KS, Kristensen BB, Kehlet H. A compression bandage improves local infiltration analgesia in total knee arthroplasty. Acta Orthopaedica. 2008;(6):806-11.

24. Andersen LO, Kristensen BB, Husted H, Otte KS, Kehlet H. Local anesthetics after total knee arthroplasty: Intraarticular or extraarticular administration? A randomized, doubleblind, placebo-controlled study. Acta Orthopaedica. 2008;79(6):800-805.

25. Andersen LO, Husted H, Kristensen BB, Otte KS, GaarnLarsen L, Kehlet H. Analgesic efficacy of intracapsular and intra-articular local anaesthesia for knee arthroplasty. Anaesthesia. 2010;65(9):904-12.

This article is also available online on the SAOA website (www.saoa.org.za) and the SciELO website (www.scielo.org.za). Follow the directions on the Contents page of this journal to access it. 